\title{
Writing Film, Writing Literature: \\ New Czech Translations of Four \\ Ingmar Bergman's Film Short Stories
}

Jan-Marek Šík

Ingmar Bergman. Hodina vlku [Hour of the Wolf]. Kniha Zlín, 2018. 262 pp.

From the narratological point of view, the term story refers to the actual chronology of events in a narrative that is independent from its representation created by a concrete medium. Czech readers still possibly know better the film interpretations of Bergman's short stories, but have now, thanks to the publishing house Kniha Zlín, got the possibility to acquaint themselves with four of his so called 'film narratives' published under the title Hodina vlku [Hour of the Wolf]. Apart from the short story of the same name (written 1966), the compilation contains texts called Shame (1967), The Passion of Anna (1968) and thematically related From the Life of Marionettes (1979). These texts came into existence during the same period as the films to which they served as a kind of manuscripts or textual outlines. The compilation was translated into Czech by Zbyněk Černík, who is also the author of the afterword that briefly introduces the context of their creation.

The first film narrative Hour of the Wolf is from the included texts disputably the most literarily experimental. Although it contains notes that make its connection with the planned movie evident (such as 'From here on, the text will be accompanied with film pictures ad libitum', p.
11, all translations are mine), the reader is at the same time somehow reluctant to believe that such a text can be picturised without further revision. The line between writing a screenplay and/or a short story is crossed at the end of the text that describes Johan's dreamlike, surreal and at the same time completely real death at the swamp. The influence of Bergman's literary model August Strindberg and his postinfernal dramatic work is apparent in this text, which blurs the differences between the basic dichotomies we think we are able to analyse in our everyday life: most importantly the empirically distinguishable reality and fantasy imposed by inner or outer powers. This blurred boundary is accentuated by the usage of metatextuality: the main female character Alma reads her husband's diary and we as readers cannot be completely sure if the narrated events belong to the diegetic or hypodiegetic level of narration, or - in another words - to the realm of fictional reality or of a - even more fictional - dream.

The second text entitled Shame takes place during a fictitious Swedish civil war. This setting is nearly an ideal background for the development of an existentially tuned plot containing not only searching for solution of conflicts between an individual human 
being and his life condition; in the focus of the narrative stands a married couple that has to react on the escalating imbalance in both the outer world and their relationship. The text in a way follows a course of the 1960s and early 1970s Swedish literature that concentrated on actual (political) topics (not at all typical for Bergman) and strove to depict them quite 'cold-bloodedly' so that the texts should resemble a documentary (which is the kind of objectiveness that Bergman's analytical style seems to tend to).

The third short story called The Passion of Anna is - as for the form - the most traditional and probably corresponds to our notion of the literature as such. It does not follow the strict marking of individual utterances that is typical of dramatic texts and screenplays. Nevertheless, it does not work consistently with indirect speech and verba dicenci, and the text thus stands in this respect somewhere between prose and dramatic narrative. This aspect is clearly visible in the passages where Bergman resorts to 'condensing' the dialog by writing the direct speeches one after the other in one sequence and uses only absolutely indispensable formal means. On the other hand, Bergman chose an intradiegetic narrator and firstperson narrative where the fictional space is perceived through the eyes of the protagonist, Andreas Winkelman, who also narrates the story from one year's distance. These two narrative methods are indisputably distant from the classical technique of textual construction of both drama and film scripts.

Even a less experienced spectator of Bergman's movies has certainly noticed the emphasis the filmmaker puts on his character's speech as well as on the scenes when the language steps aside and leaves more space and time to visual representation. Literature, being in its typical form purely a verbal art, allows Bergman to further elaborate the tension between the told and the untold; unlike Bergmanfilmmaker, Bergman-writer can simply allow himself the luxury of not representing anything at all if he does not want to. One example can be the end of The Passion of Anna: after Anna's silence and Andreas' fury have caused the final catastrophe, the reader perceives the end of the story only through Andreas' (or more precisely his one year older self) fragmentary memory of the event.

One way of expression that Bergmanwriter borrows from Bergman-filmmaker (or vice versa, as they are indeed inseparable) is the conciseness of depiction that clearly reminds of screenplays. Sentences such as 'Me and mistreating animals, says the old man and grimaces pitifully (attempt to laugh),' (128) can make the reader think about what in literature really bears any meaning and has its undisputable place in the text, and what serves only as a filler between particular meaningful elements. The filmmaker cannot nevertheless stay silent: for example, in From the Lives of Marionettes, we are told at the beginning of every scene which colour of the film should be used. The above mentioned text also brings quite an extraordinary experience for a reader of a 'common' fiction since it includes a long monologue of the protagonist, Peter Egerman, that is framed as a letter describing his erotically and existentially loaded dream. Suddenly, we realize that a new voice talks to us from the brackets - the voice of the Bergman-filmmaker himself, pondering and polemicising over 
the problems of depicting the text's content on a film stock and limits of cinematography as such: 'I write down my words representing pictures that I see flashing in front of my eyes. There are no practical solutions, maybe they will appear, maybe not. I do not know. We can show burning skyscrapers or big apes, it costs money and effort, but it can be solved. But how can we show a mental process?' (191).
Bergman's film narratives stand between literature and screenplays: through film methods, they bring revealing moments into our understanding of how literature works. Their somehow simplified form (compared to the 'traditional' prose) serves primarily to deliver a deep message about the conditions of human existence. Bergman achieves this without surplus of insignificant words: a quality of a real picture maker. 